Send your research letters to the editor, British Dental Journal, 64 Wimpole Street, London W1G 8YS or by email to bdj@bda.org Priority will be given to letters less than 500 words long. Letters should be typed. Authors must sign the letter, which may be edited for reasons of space

\section{Steroid cover}

Sir, the paper by Drs Gibson and Ferguson (BDJ 2004, 197: 681-685) reviews this controversial field well. In their introduction, they refer to a previous edition of Medical Problems in Dentistry (1998). This was written about 5 years ago, based on the evidence then available. The current (2004) edition states "Although the evidence for the need for steroid cover may be questionable, medico-legal and other considerations suggest that one should act on the side of caution and fully inform and discuss with the patient, take medical advice in any case of doubt and give a steroid cover unless quite confident that collapse is unlikely"

Although Gibson and Ferguson make no reference to our initial recent recommendations, our last conclusion is not too dissimilar to their conclusions though perhaps a little more cautious.

It may also be relevant that the UK MHRA (Medicines and Healthcare Products Regulatory Agency) and CSM (Committee of Safety of Medicines) together published recommendations which appear not yet to have been superseded, that include "Patients who encounter stresses such as trauma, surgery or infection and who are at risk of adrenal insufficiency should receive systemic corticosteroid cover during these periods. This includes patients who have finished a course of systemic corticosteroids of less than three weeks duration in the week prior to the stress. Patients on systemic corticosteroid therapy who are at risk of adrenal suppression and are unable to take tablets by mouth should receive parenteral corticosteroid cover during these periods."

(http://www.mca.gov.uk/ourwork/monitor safequalmed/currentproblems/volume24 may.htm)

\section{Scully}

London

doi: 10.1038/sj.bdj.4812225

\section{Clinical trials}

Sir, we read with interest the paper by C S Jones, R W Billington and G J Pearson

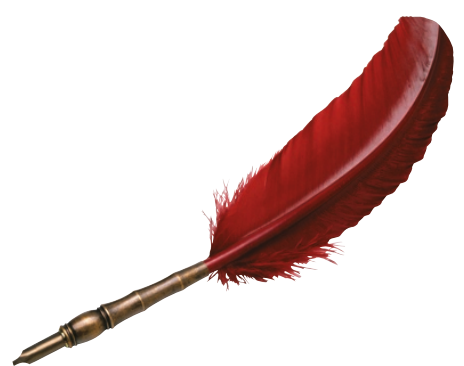

(BDJ 2004, 197:311-313) on the advantages and disadvantages of running clinical trials in general practices.

What is unclear from this paper is whether the practitioners were collaborators in this study or merely data collectors for academics. This paper, in our opinion, gives a very one sided view of practitioner involvement in a clinical trial. The authors make a number of suggestions as to the reasons why this particular clinical trial failed. In view of the title of the paper we would have expected the researchers to have reviewed and included the practitioners' experiences e.g. were they involved and happy with the design of the study, did they get comprehensive training and the necessary support during the trial and were they adequately funded?

It was clear from the review of the NHS National Programme in Primary Dental Care Research and Development Programme at the 'Reflection and Moving forward' Dental R \& D Conference that general dental practitioners can lead and collaborate with academics in delivering successful research projects. Two recent publications have demonstrated how this can be achieved. ${ }^{1,2}$

There is no doubt that there is a paucity of evidence underpinning the science of dentistry. As $90 \%$ of patient care is provided in the primary care setting it is appropriate that this is where research should be undertaken rather than in academic settings.

A number of primary dental care research networks exist where primary care practitioners are involved in adding to the evidence necessary for improving patient care. We hope that those wishing to carry out clinical trials in general practice will not be discouraged by the conclusions drawn by the authors of this paper.

\section{N. Palmer, Liverpool}

\section{E. Kay, Manchester}

1. Kay E J, Ward N, Locker D. A General dental practice network - philosophy, activities and participant views. Br Dent J 2003;194:545-549.

2. Kay E J, Ward N, Locker D. A general dental practice network: impact of oral health in general denta practice patients Br Dent J 2003 ;194:621-625.
The authors of the paper respond: We thank Professor E Kay and Dr N Palmer for their interest in our paper. We wholeheartedly agree with their comments in their final paragraph that as the majority of patient care takes place in general practice this is the obvious place for such research to be undertaken. Indeed we did specifically state that the first of the references they cite ${ }^{1}$ was similar to the improved procedure we suggested.

As we indicated in our reply to comments by Crisp and Burke, (BDJ 2005, 198:282) the practitioners were involved from the outset with practice visits, training sessions and material to try before committing themselves to the project. We also discussed the funding with them at this stage. Throughout the running of the trial they were in contact with the organisers. All the clinical procedures they were asked to use were ones they routinely used in practice. The only slightly novel element was the test restorative material. This had been commercially available for about 5 years before the trial started and GDPs on the PREP panel placed 215 restorations without any reported difficulty. ${ }^{2}$ In addition, the two clinical authors (CSJ and GJP) had found the material easy to use in the restorative applications that were the subject of the trial, in general practice.

We agree with correspondents about the possibility of satisfactory collaboration between GDPs and academics and would again refer to Knibbs work with which two

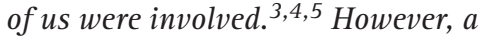
controlled clinical trial is very different to clinical evaluations and audits which have both been very successful carried out by both Knibbs et al at Birmingham and by Burke's PREP panel and by others.

1. Kay E J, Ward N, Locker D. A general practice research network-philosophy, activities and participants views. Br Dent J 2003; 194:545-549.

2. Burke FJ T. Prep Panel Evaluation of HI-DENSE. Dental Practice September 21st 1995.

3. Knibbs P J, Plant C G, Shovelton D S. An evaluation of an anhydrous glass-ionomer in general dental practice. BrDent J 1986; 160:170-173.

4. Knibbs P J, Plant C G, Pearson G J. A clinical assessment of an anhydrous lass-ionomer cement. BrDent J 1986; 161:99-103. 
5. Knibbs P J, Plant C G. An evaluation of a rapid setting glass-ionomer cement in general dental practice. Aust Dent J 1989; 34:459-465.

doi: $10.1038 /$ sj.bdj.4812226

\section{Indices}

Sir, as dentists with extensive experience of primary dental care, we have enjoyed the series on research in dental practice. However, we were somewhat perturbed, in paper 4 on Measures (BDJ 2004, 197:739746), that Clinical Outcome measures included the likes of DMFT/dmft, CPITN, IOTN, TSIF and a number of patient based outcome measures, but did not include the Oral Health Index $(\mathrm{OHX})^{1}$ or its variant, the Denplan Oral Health Score (OHS).

These indices are now used on a daily basis in UK dental practices, and, with over well over 1,000,000 0HS scores having been recorded in Denplan Excel practices, this represents, by far, the most widespread acceptance of a 'composite' index of oral health. The OHX and/or OHS have been found to be well accepted by general dental practitioners ${ }^{2}$, have found favour with patients as a means of communicating oral health ${ }^{3}$ and have demonstrated good inter- and intraexaminer reliability ${ }^{4,5}$. These indices fulfil all the properties of an ideal outcome measure quoted by the authors of the paper, hence our mystification at their omission.

\section{F. J. T. Burke, Birmingham \\ M. Busby, Winchester}

1. Burke FJ T, Wilson N H F. Measuring oral health: an historical view and details of a contemporary oral health index (OHX). Int Dent J 1995; 45;358-370.

2. Burke FJ T, Busby M, McHugh S, Delargy S, Mullins A, Matthews R. Evaluation of an oral health scoring system by dentists in general dental practice. BrDent J 2003:194:215-218.

3. Burke FJ T, Busby M, McHugh S, Delargy S, Mullins A, Matthews R. A pilot study of patients'views of an oral health scoring system. Primary Dent Care 2004 11:37-39

4. Delargy S, McHugh S, Hall AC, Burke FJ T. Reproducibility of an Index of Oral Health among general dental practitioners. J Dent Res 2003:82 (Spec Issue) C-532 Abs. No.416.

5. Busby M, Delargy S, Mc. Hugh S, Matthews R, Burke F J T. Reproducibility of an Oral Health Score among general dental practitioners. J Dent Res 2003; 82 (Spec Issue) C-532 Abs. No.417.

One of the authors of the paper T Newton responds: Our list of measures was not intended as a comprehensive list of measures. We are grateful to Professor Burke and Dr Busby for drawing the attention of readers of the $\mathrm{BDJ}$ to these scales.

doi: 10.1038/sj.bdj.4812227

\section{Chronic pain}

Sir, we have the great good fortune of working in a profession which can make a real difference to people's quality of life. I would be grateful for the opportunity to share this 'good news' story with your readers.

Recently a patient came to me with a history of severe chronic pain for eight years. Teeth which had been identified as the source of the pain had been rootfilled bringing no relief from the pain. They had then been removed, but still brought no relief from the pain.

After five years she was referred to the Chronic Pain Clinic and was given a MRI scan which diagnosed a "compressed trigeminal nerve'. She underwent an operation to the base of her skull to relive this 'compression' only to awake to the same symptoms as before but now she had the additional problem of intractable pain across the whole of the other side of her face, down the neck and arm on that other side. For two years the CPC tried to diagnose her trouble and have come up with 'atypical facial pain'. She understandably arrived in my practice in a distressed state of despair.

Palpation of all muscles of the head and neck produced moderate to severe sensitivity. Intra-orally the restorative and periodontal state of her mouth was healthy.

Having undertaken training with Bill Comcowich and Roy Higson on the principles and application of occlusion, I noticed that she had a very slight discrepancy between centric occlusion (CO) and centric relation (CR). With nothing for the patient to lose but her pain I recommended that I make her a Lucia Jig to wear at night and then I would review her after two night's use. Two days later a transformed lady walked into the practice.

Since wearing the Lucia Jig she has had no pain and has needed no painkillers! Her whole demeanour has changed and she looks wonderfully relieved to feel happy with life for the first time in years. Now starts the meticulous process of correctly identifying her centric relation and then equillibrating her teeth so that $\mathrm{CO}=\mathrm{CR}$.

It is on days like these that one realises what a huge privilege we have, through our diligence, to be able to transform another person's quality of life.

\section{Marks}

\section{Southampton}

doi: 10.1038/sj.bdj.4812228

\section{Rubber dams}

Sir, I felt I must contact the $B D J$ after reading the paper in $B D J$ 2004, 197:527. This, I believe, is the 6th in a series of endodontic papers and covered the subject of rubber dam.

I agree with Dr Carrotte that the use of rubber dam may protect patients from inhalation or ingestion of foreign materials at the time of restorative dental work being carried out. I also believe that where inhalation is suspected, in either an adult or a child, further investigation is required. The Royal College of Radiologists have produced guidelines for clinicians which, among other topics, covers the situation of foreign body inhalation/ingestion. In the adult patient without abdominal signs or symptoms the only radiograph indicated would be an Antero-Posterior Chest Film. ${ }^{1}$

Figure 1 in the paper by Dr Carrotte claims to show 'An endodontic instrument has been inhaled due to a lack of airway protection.' This is incorrect. The Figure 1 radiograph is in fact a plain abdominal film showing a small, radio-opaque abnormality (possibly a foreign body; and possibly even an endodontic instrument) lying at the level of L1-L2. I think this merits a mention as this radiograph would not be indicated in most cases and in fact represents ingestion rather than

inhalation, if indeed it represents either. M. F. Devlin

By email

1. Making the best use of a Department of Clinical Radiology. Guidlines for Doctors. Fifth Edition. Royal College of Radiologists. ISBN 1872599885

Author of the paper P Carrotte responds: I am grateful to $\mathrm{Mr}$ Devlin for his observations, indeed I would like to thank all those who have contacted me either by letter or e-mail with interesting and often helpful comments related to this series of endodontic papers.

In reply to Mr Devlin, may I first say that I was sorry that he chose to doubt what could clearly be seen on the original and full sized radiograph. That aside, the picture was intended to illustrate one of the serious consequences of not using rubber dam during root canal treatment and not to give radiographic advice, but I am indeed grateful to Mr Devlin for drawing the Royal College of Radiologist's Guidelines to the attention of the dental profession.

It would appear that these may not have been as widely disseminated as the College would wish, as several colleagues to whom I have spoken would have ordered a plain abdominal film in the unfortunate event of loss of a sharp object by ingestion or inhalation.

Having read a copy of the guidelines I find that they are, in fact, both detailed and complicated depending upon several different case scenarios, and the prudent clinician would obviously be advised to seek professional radiographic guidance in this unfortunate situation. This will certainly be discussed in the next edition of the BDA's textbook A Clinical Guide to Endodontics from which the papers were taken.

doi: $10.1038 /$ sj.bdj.4812229 